\title{
Inspiratory Muscle Strength and Endurance in Children and Adolescents with Cystic Fibrosis
}

\author{
Fernanda M Vendrusculo PT MSc, João P Heinzmann-Filho PT PhD, Taila C Piva PT, \\ Paulo JC Marostica MD PhD, and Márcio VF Donadio PT PhD
}

\begin{abstract}
BACKGROUND: Pulmonary changes that occur in cystic fibrosis may influence inspiratory muscle strength and endurance. We evaluated inspiratory muscle strength and endurance in children and adolescents with cystic fibrosis in comparison with healthy subjects. METHODS: This is a crosssectional observational study with subjects with cystic fibrosis and paired healthy individuals, age 6-18 y. Spirometry, impulse oscillometry, plethysmography, manovacuometry, and a protocol of inspiratory muscle endurance were performed. RESULTS: Subjects with cystic fibrosis $(n=34)$ had higher maximum percent-of-predicted inspiratory pressure $\left(P_{\operatorname{Imax}}\right)$ than healthy $(n=68)$ subjects $(118.5 \pm 25.8 \%$ vs $105.8 \pm 18.0 \%)$ and no significant difference in endurance $(60.9 \pm 13.3 \%$ vs $65.3 \pm 12.3 \%$ ). When restricting the analysis to subjects without Pseudomonas aeruginosa colonization and with $\mathrm{FEV}_{\mathbf{1}}>\mathbf{8 0 \%}, \mathrm{P}_{\text {Imax }}$ values were significantly higher, and inspiratory muscle endurance was lower, in comparison with the control group. $\mathbf{P}_{\text {Imax }}$ correlated significantly with FVC $(\mathrm{r}=0.44, P=.02)$ and $\mathrm{FEV}_{1}(\mathrm{r}=0.41, P=.02)$, whereas endurance correlated better with total airway resistance $(r=0.35, P=.045)$ and with central airway resistance $(r=0.48, P=.004)$. CONCLUSIONS: Children and adolescents with cystic fibrosis with no colonization by $P$. aeruginosa and normal lung function present increased inspiratory muscle strength and decreased endurance compared with healthy individuals, indicating that changes in the respiratory muscle function seem to be distinctly associated with pulmonary involvement. Strength was related to pulmonary function parameters, whereas endurance was associated with airway resistance. Key words: cystic fibrosis; child; adolescent; respiratory muscles. [Respir Care 2016;61(2):184-191. (C) 2016 Daedalus Enterprises]
\end{abstract}

\section{Introduction}

Cystic fibrosis is a disease characterized by progressive loss of pulmonary function, with obstruction of the airways caused by abnormal production of mucus and by the

\footnotetext{
Ms Vendrusculo and Mr Heinzmann-Filho are affiliated with Centro Infant, Institute of Biomedical Research, Pontifícia Universidade Católica do Rio Grande do Sul (PUCRS), Porto Alegre, RS, Brazil. Ms Piva is affiliated with the School of Nursing, Nutrition and Physiotherapy, PUCRS, Porto Alegre, RS, Brazil. Dr Marostica is affiliated with the School of Medicine, Universidade Federal do Rio Grande do Sul (UFRGS), Porto Alegre, RS, Brazil. Dr Donadio is affiliated with Centro Infant, Institute of Biomedical Research, PUCRS, Porto Alegre, RS, Brazil.
}

Mr Heinzmann-Filho received a scholarship from Coordenação de Aperfeiçoamento de Pessoal de Nível Superior. Ms Piva received a scholarship from Conselho Nacional de Desenvolvimento Científico e Tecnológico. The remaining authors have disclosed no conflicts of interest. presence of chronic inflammation and recurring infections. ${ }^{1}$ Respiratory muscle strength has been much evaluated in these subjects, but studies are still contradictory. ${ }^{2}$ Some authors report that strength may be within normality or even increased, suggesting a muscle training effect in response to airway obstruction and chronic coughing. ${ }^{3,4}$ On the other hand, authors who demonstrate a diminished strength associate muscle weakness with hyperinflation and malnutrition, ${ }^{5}$ suggesting that these subjects are not

\footnotetext{
Correspondence: Marcio Donadio PT PhD, Centro Infant, Instituto de Pesquisas Biomédicas (IPB), Av. Ipiranga, 6690, $2^{\circ}$ andar, Lab. 13, Porto Alegre, Rio Grande do Sul, CEP 90610-000, Brazil. E-mail: mdonadio@pucrs.br.
}

DOI: $10.4187 /$ respcare. 04231 
able to maintain muscle strength at advanced stages of the disease. ${ }^{6}$

Although measuring maximum static pressures supplies information about strength, it does not quantify inspiratory muscle endurance. ${ }^{7}$ Evidence shows that the evaluation of muscle endurance may be more relevant than strength in subjects with chronic obstructive pulmonary disease, $, 8,9$ since endurance is the capacity of a muscle or a muscle group to sustain a given task over time and is directly related to muscle fatigue. ${ }^{10}$ However, few studies have evaluated inspiratory muscle endurance in subjects with cystic fibrosis, and these have shown contradictory results, just as for muscle strength. One previous study showed an apparent increase of endurance due to the adaptation of the muscles to the chronic stress of ventilating against a load generated by airway obstruction. ${ }^{11}$ On the other hand, there is evidence that endurance may be diminished independent of nutritional status, the presence of airway obstruction, pulmonary hyperinflation, respiratory muscle strength, or maximum exercise capacity ${ }^{3,12}$ and may be a major parameter to evaluate dyspnea in subjects with cystic fibrosis. ${ }^{12}$ The individuals with cystic fibrosis who have a reduced capacity to contract the respiratory muscles become more susceptible to muscle fatigue with a limitation in the ability to carry out prolonged activities or tasks. However, the degree of inspiratory muscle endurance impairment and how that impairment is associated with important lung function parameters in children and adolescents with cystic fibrosis remain poorly understood.

Pseudomonas aeruginosa is the most common pathogen in cystic fibrosis lung disease and is associated with gradual decline of pulmonary status in children and young adults. ${ }^{13}$ Once infection is established, there is an accelerated decline in lung function, quality of life, and survival. ${ }^{14,15}$ Furthermore, chronic $P$. aeruginosa infection has been related to decreased maximum inspiratory pressure $\left(\mathrm{P}_{\text {Imax }}\right)$ and is probably an independent predictor of respiratory muscle compromise in cystic fibrosis, ${ }^{16}$ although its relation to muscle endurance remains unclear.

The aim of our study was to evaluate muscle strength and inspiratory muscle endurance in children and adolescents with cystic fibrosis and to compare them with agematched healthy controls. The role of P. aeruginosa and lung function compromise was assessed, and we further examined possible associations of strength and endurance with other pulmonary function parameters, such as $\mathrm{FEV}_{1}$, total lung capacity, residual volume (RV), and airway resistance. A better understanding of inspiratory muscle strength and endurance could contribute to the development of earlier preventive measures and help in the therapeutic intervention processes in cystic fibrosis.

\section{QUICK LOOK}

\section{Current knowledge}

Cystic fibrosis is a disease characterized by progressive loss of pulmonary function, with obstruction of the airways caused by abnormal production of mucus and by the presence of chronic inflammation and recurring infections. These pulmonary derangements can negatively impact inspiratory muscle strength and endurance.

\section{What this paper contributes to our knowledge}

Children and adolescents with cystic fibrosis, but without Pseudomonas aeruginosa colonization and $\mathrm{FEV}_{1}>80 \%$, had increased inspiratory muscle strength and decreased endurance compared with healthy individuals. Strength was related to pulmonary function parameters, whereas endurance was associated with airway resistance. These findings suggest that changes in respiratory muscle function were associated with pulmonary involvement.

\section{Methods}

A cross-sectional observational study was performed in children and adolescents with cystic fibrosis, age 6-18 y, who were regularly followed at the cystic fibrosis outpatient clinics of São Lucas Hospital at Pontifícia Universidade Católica do Rio Grande do Sul (PUCRS), Porto Alegre, Brazil. Healthy children, age 6-18 y, from 1 private and 2 public schools in Porto Alegre also participated in the study. Healthy individuals were paired with children and adolescents with cystic fibrosis using the variables sex, age, height, and weight, at a proportion of 2 healthy controls for each subject with cystic fibrosis. Subjects who presented signs indicating pulmonary exacerbation, such as a temperature, increased coughing, and sputum production, were excluded. Likewise, children and adolescents who were unable to understand how the pulmonary function tests were performed or could not do them correctly were also excluded from the study. Data were collected from November 2012 to November 2013.

Sample size was estimated based on inspiratory muscle endurance (in percent of maximum inspiratory pressure $\left[\mathrm{P}_{\text {Imax }}\right]$ ) data from the study by De Jong et $\mathrm{al}^{3}$ with a mean of $48.0 \%$ and an SD of $12.0 \%$. Adopting a significance level of 0.05 , a power of $90 \%$, and a minimum difference of 10.0 , the estimated sample size was approximately 34 individuals with cystic fibrosis and 68 healthy controls. The study was approved by the Ethics in Research Committee of the Pontifical Catholic University of Rio Grande do Sul under number 04850312.9.0000.5336. Parents or legal guardians signed the free and informed consent form before inclusion in the study. 
Eligible subjects selected were invited to participate in the study at the time they came to the cystic fibrosis out-patient clinics at São Lucas Hospital-PUCRS. They were then referred to the Institute of Biomedical Research at PUCRS to undergo the procedures in the following order: anthropometric evaluation, impulse oscillometry, plethysmography, spirometry, manovacuometry, and respiratory muscle endurance protocol.

Likewise, healthy children and adolescents underwent the following procedures at their schools: anthropometric assessment, manovacuometry, and respiratory muscle endurance protocol. Only individuals who did not have respiratory illnesses evaluated by a pediatric pulmonologist (PJCM) using a respiratory health questionnaire based on the questionnaire recommended by the American Thoracic Society, Division of Lung Diseases (ATS-DLD-78-C), previously adapted and validated for use in Brazil, ${ }^{17}$ were included.

Anthropometric evaluation was performed by measuring weight and height in triplicate or until 2 identical values were obtained using a digital scale (G-Tech, Glass 1 FW, Rio de Janeiro, Brazil) previously calibrated to a $100 \mathrm{~g}$ precision and a portable stadiometer (AlturaExata, TBW, São Paulo, Brazil) with a $1 \mathrm{~mm}$ precision, ${ }^{18}$ respectively. Body mass index (BMI) $\mathrm{Z}$ score was calculated using the program WHO Anthroplus. ${ }^{19}$

Evaluation of airway resistance was performed using impulse oscillometry (Erich Jaeger, Friedberg, Germany). Tests were performed with the subject in the seated position, using a nose clip, and cheeks were supported by the examiner. Subjects were told to breathe through a mouthpiece, spontaneously, at tidal volume rate. At least 3 acceptable and reproducible measures were required for validity. Impulse oscillometry data were considered acceptable when correlation between oscillatory pressure and flows used to calculate resistance and reactance was $>0.8$. Parameters used for analysis were total resistance of the airways (R5), central resistance of the airways (R20), resistance of the airway at a frequency of $10 \mathrm{~Hz}(\mathrm{R} 10)$, and resonance frequency $\left(f_{\text {res }}\right)$. Data were expressed in absolute values and in percentages of the predicted reference values for oscillometry. ${ }^{20}$

Pulmonary volumes, including total lung capacity, functional residual capacity, and RV, were measured by whole body plethysmography. The equipment used was the Vmax 22 (Viasys Healthcare, Hörchberg, Germany) plethysmograph. Tests were performed, and criteria of acceptability and reproducibility were applied in accordance with American Thoracic Society/European Respiratory Society guidelines. ${ }^{21}$ Briefly, tests were performed with the subject seated, inside the closed booth, in a comfortable position. A series of 3-5 technically satisfactory maneuvers were performed. Tests would be considered valid when at least 3 acceptable and reproducible maneuvers were obtained, with a variation of $<5 \%$. Data were expressed in absolute values and in percentage of the predicted, using the equations of Koopman et al. ${ }^{22}$

Lung function was performed using a flux-based spirometer (KoKo, Louisville, Colorado). Spirometric parameters evaluated included $\mathrm{FEV}_{1}, \mathrm{FVC}$, and forced expiratory flow between 25 and $75 \%$ of vital capacity. Spirometry was performed in the standing position without using a nose clip, ${ }^{23}$ followed by quick maximum inspiration sustained for at least $3 \mathrm{~s}$. Three acceptable curves and 2 reproducible curves were obtained. ${ }^{24}$ The international equation GLI $2012^{25}$ was used to normalize the spirometric data.

The strength of the inspiratory muscles was evaluated using a digital manuvacuometer (MVD 500, Globalmed, Scottsdale, Arizona) by measuring $\mathrm{P}_{\mathrm{Imax}}$, with the subject in the sitting position. A connector was used between the mouthpiece and the apparatus with an orifice to reduce the pressure generated in the oral cavity. Subjects with cystic fibrosis and healthy controls were told to perform maximum inspiration against the occluded valve, using a nose clip, based on the residual volume. Five maneuvers were performed, at 40-s intervals between one maneuver and the other, and the highest value recorded in $\mathrm{cm}_{2} \mathrm{O}$, was used for the study. Data were expressed in absolute values and percentage of predicted. ${ }^{26,27}$

After $\mathrm{P}_{\text {Imax }}$ evaluation, a protocol of inspiratory muscle endurance was performed through a linear load device (Threshold-IMT, Philips Respironics, Murrysville, Pennsylvania) during an incremental loading test to measure inspiratory muscle endurance. The spring and structure of the apparatus were modified to obtain pressures of $>41 \mathrm{~cm} \mathrm{H}_{2} \mathrm{O}$. With the help of the Biomedical Engineering Department of PUCRS, based on a commercial spring from the Threshold-IMT, a new stainless steel spring was made with an elastic constant of 0.035 newtons $/ \mathrm{mm}$, thus allowing us to obtain pressures up to $145 \mathrm{~cm} \mathrm{H}_{2} \mathrm{O}$. Subjects began the protocol inspiring against a fixed load of $30 \%$ of $\mathrm{P}_{\text {Imax }}$ during $2 \mathrm{~min}$. To begin the inspiratory flow, it was necessary to generate a sufficient inspiratory pressure to open the valve. Every $2 \mathrm{~min}$, the load was increased by $10 \%$ of $\mathrm{P}_{\text {Imax }}$. The maximum load was defined as the highest percentage of $\mathrm{P}_{\text {Imax }}$ achieved and maintained for at least 1 min. ${ }^{3}$ The breathing pattern was controlled and maintained at 20 respiratory incursions/min. The interruption criteria of the protocol were intense fatigue or failure to open the valve at least 3 consecutive times. At the beginning of the protocol and in the last $10 \mathrm{~s}$ of each level of loading, subjects were asked to classify the subjective degree of dyspnea using the modified Borg scale.

\section{Statistical Analysis}

Distribution of variables was evaluated using the Kolmogorov-Smirnov test, and, since they presented a normal 
Table 1. Characterization of the Study Population

\begin{tabular}{lccc}
\hline \hline & $\begin{array}{c}\text { Healthy } \\
(n=68)\end{array}$ & $\begin{array}{c}\text { Cystic Fibrosis } \\
(n=34)\end{array}$ & $P$ \\
\hline Age, y & $13.9 \pm 2.6$ & $14.0 \pm 2.7$ & .80 \\
Male sex & $58.8 \%$ & $58.8 \%$ & \\
Weight, kg & $48.6 \pm 12.7$ & $46.2 \pm 14.3$ & .39 \\
Height, cm & $155.7 \pm 12.9$ & $154.7 \pm 14.9$ & .71 \\
BMI & & & \\
$\quad$ Absolute, $\mathrm{kg} / \mathrm{m}^{2}$ & $19.7 \pm 3.1$ & $18.8 \pm 3.3$ & .21 \\
$\quad$ Z score & $0.06 \pm 0.99$ & $-0.37 \pm 1.17$ & .055 \\
$\mathrm{P}_{\text {Imax }}$ & & & \\
$\quad$ Absolute, cm $\mathrm{H}_{2} \mathrm{O}$ & $110.9 \pm 23.7$ & $119.03 \pm 20.7$ & .09 \\
$\quad$ \% predicted & $105.8 \pm 18.0$ & $118.5 \pm 25.8$ & .005 \\
Endurance & & & \\
$\quad$ Absolute, cm $\mathrm{H}_{2} \mathrm{O}$ & $72.8 \pm 21.5$ & $73.2 \pm 22.3$ & .92 \\
$\quad$ Percentage & $65.3 \pm 12.3$ & $60.9 \pm 13.3$ & .10 \\
& & & \\
\hline Values are expressed as mean \pm SD, except for male sex (\%). & & \\
BMI = body mass index & & & \\
$\mathrm{P}_{\text {Imax }}=$ maximum inspiratory pressure & & \\
\hline
\end{tabular}

distribution, the continuous variables were presented as mean and SD. Categorical variables were presented in absolute and percentage frequencies. Correlations were evaluated using Pearson's linear correlation test. Differences between subjects with cystic fibrosis and healthy individuals were evaluated using the Student $t$ test for independent samples. All of the analyses and data processing were performed using SPSS 18.0 (SPSS, Chicago, Illinois). The level of significance was accepted whenever $P$ was $\leq .05$.

\section{Results}

Thirty-four children and adolescents with cystic fibrosis, age $6-18 \mathrm{y}$, mean age $14.0 \pm 2.7 \mathrm{y}$, were included; 20 of the subjects (58.8\%) were male. Six subjects who did not manage to perform plethysmography correctly were excluded from the study, so that lung volume results are presented with a final number of 28 individuals. Subjects with cystic fibrosis presented a mean percent-of-predicted $\mathrm{P}_{\text {Imax }}$ of $118.5 \pm 25.8 \%$ and a mean endurance (percent of $\mathrm{P}_{\mathrm{Imax}}$ ) of $60.9 \pm 13.3 \%$. Sixty-eight healthy children and adolescents were also included, paired by sex, age, weight, and height, with a mean percent-of-predicted $\mathrm{P}_{\text {Imax }}$ of $105.8 \pm 18.0 \%$ and endurance of $65.3 \pm 12.3 \%$. There was no significant difference between subjects with cystic fibrosis and healthy individuals when age, weight, height, and BMI were compared. As to $\mathrm{P}_{\text {Imax }}$, subjects with cystic fibrosis presented significantly greater strength than healthy children. On the other hand, no significant difference was found in endurance between subjects with cystic fibrosis and healthy individuals. Table 1 presents the data that characterize the study population.
Table 2. Pulmonary Function Values of the Cystic Fibrosis Subjects

\begin{tabular}{|c|c|c|}
\hline Variables & Absolute & $\%$ Predicted \\
\hline \multicolumn{3}{|l|}{ Spirometry $(n=34)$} \\
\hline FVC, L & $2.94 \pm 0.99$ & $88.9 \pm 23.8$ \\
\hline $\mathrm{FEV}_{1}, \mathrm{~L}$ & $2.31 \pm 0.90$ & $80.1 \pm 27.7$ \\
\hline $\mathrm{FEV}_{1} / \mathrm{FVC}$ & $0.77 \pm 0.12$ & \\
\hline $\mathrm{FEF}_{25-75 \%}, \mathrm{~L} / \mathrm{s}$ & $2.22 \pm 1.22$ & $65.0 \pm 34.3$ \\
\hline \multicolumn{3}{|c|}{ Impulse oscillometry $(n=34)$} \\
\hline $\mathrm{R} 5, \mathrm{kPa} / \mathrm{L} / \mathrm{s}$ & $0.58 \pm 0.21$ & $125.8 \pm 38.7$ \\
\hline $\mathrm{R} 20, \mathrm{kPa} / \mathrm{L} / \mathrm{s}$ & $0.40 \pm 0.10$ & $116.3 \pm 22.7$ \\
\hline $\mathrm{R} 5$ - R20 (\%) & $23.30 \pm 15.71$ & \\
\hline $\mathrm{f}_{\text {res }}, \mathrm{Hz}$ & $17.61 \pm 5.49$ & \\
\hline \multicolumn{3}{|c|}{ Plethysmography $(n=28)$} \\
\hline TLC, L & $4.29 \pm 0.86$ & $97.7 \pm 11.8$ \\
\hline FRC, L & $2.11 \pm 0.60$ & $71.9 \pm 14.9$ \\
\hline $\mathrm{RV}, \mathrm{L}$ & $1.31 \pm 0.52$ & $137.0 \pm 53.9$ \\
\hline RV/TLC & $0.31 \pm 0.12$ & \\
\hline
\end{tabular}

$\overline{\text { Values are expressed as mean } \pm \text { SD. }}$.

$\mathrm{FEF}_{25-75 \%}=$ forced expiratory flow between 25 and $75 \%$ of vital capacity

$\mathrm{R} 5=$ total resistance of airways

$\mathrm{R} 20=$ central resistance of airways

$\mathrm{f}_{\text {res }}=$ resonance frequency

TLC $=$ total lung capacity

$\mathrm{FRC}=$ functional residual capacity

$\mathrm{RV}=$ residual volume

Table 2 presents pulmonary function data, including $\mathrm{FEV}_{1}, \mathrm{FVC}, \mathrm{R} 5$, R20, total lung capacity, functional residual capacity, and RV, of subjects with cystic fibrosis. In general, results were within or close to the limits of normality. When correlating $\mathrm{P}_{\mathrm{Imax}}$ and endurance with other variables of pulmonary function tests in subjects with cystic fibrosis, there was a significant correlation of $\mathrm{P}_{\text {Imax }}$ with FVC (r $=0.44, P=.02)$ and $\mathrm{FEV}_{1}(\mathrm{r}=0.41$, $P=.02)$. On the other hand, endurance presented a correlation with airway resistance in both $\mathrm{R} 5(\mathrm{r}=0.35$, $P=.045)$ and $\mathrm{R} 20(\mathrm{r}=0.48, P=.004)$. Fig. 1 shows the graphs of the correlations found. In addition, there was a significant correlation of BMI Z score with $\mathrm{P}_{\operatorname{Imax}}(\mathrm{r}=0.34$, $P=.048)$ but not with endurance $(\mathrm{r}=0.05, P=.77)$.

Subjects with cystic fibrosis chronically colonized by $P$. aeruginosa presented a significantly lower $\mathrm{FEV}_{1}$ $(P=0.046)$ and higher R5 $(P=.001)$ and R20 $(P=.002)$ than the non-colonized ones. Likewise, subjects with $\mathrm{FEV}_{1}<80 \%$ presented R5 $(P=.001)$, functional residual capacity $(P=.025)$, and $\mathrm{RV}(P=.001)$ significantly greater than subjects with $\mathrm{FEV}_{1}>80 \%$. Next, strength and endurance of children's and adolescents' inspiratory muscles were compared. They were divided into groups with or without chronic P. aeruginosa colonization and with an $\mathrm{FEV}_{1}$ greater or smaller than $80 \%$ of predicted and were compared with their healthy peers. A significantly greater $\mathrm{P}_{\text {Imax }}$ (Fig. 2, A and C) was shown in subjects with cystic fibrosis without $P$. aeruginosa colonization (119.54 \pm 27.4$)$ compared with healthy individuals 

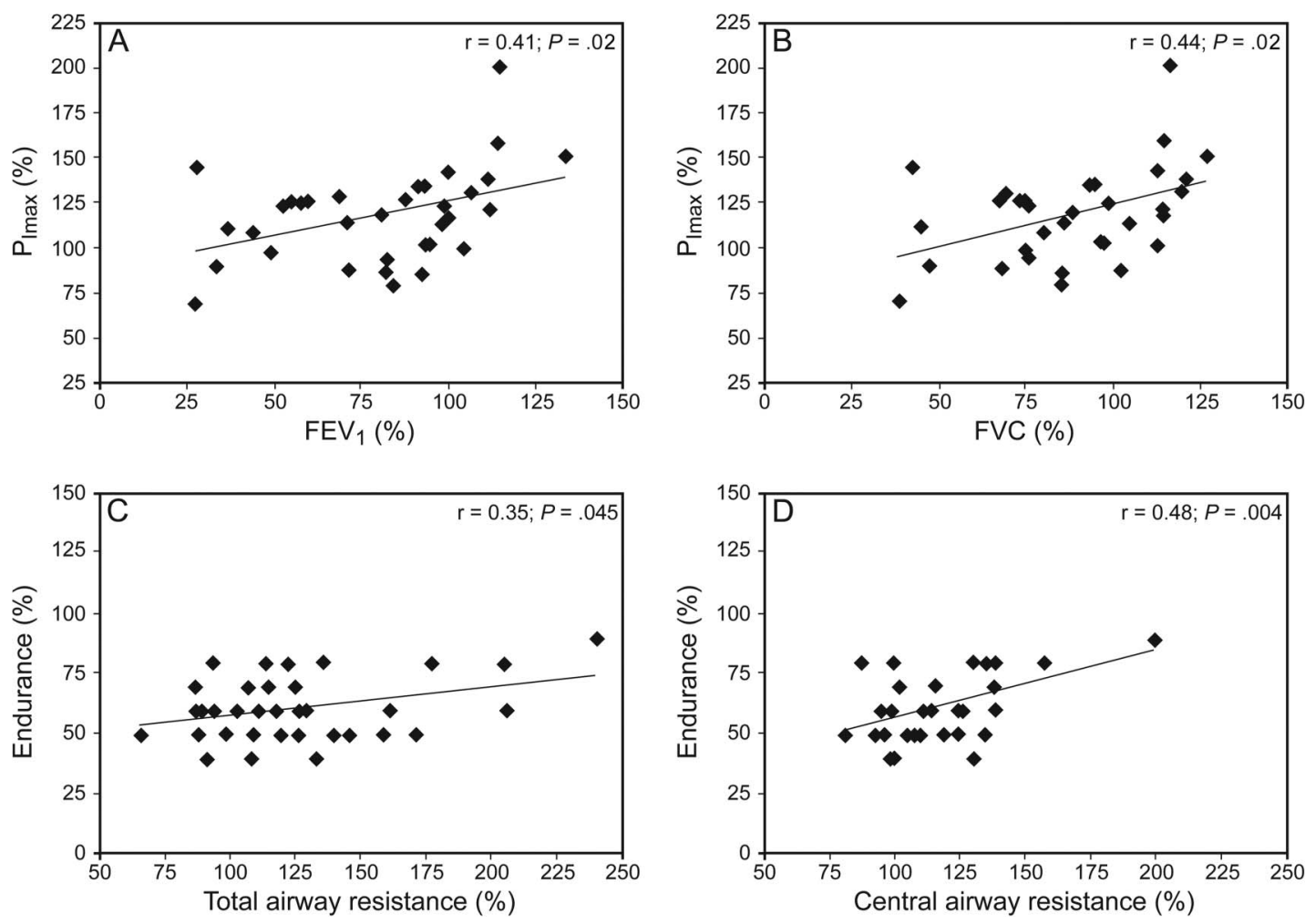

Fig. 1. Correlations between inspiratory muscle strength, endurance, spirometry, and impulse oscillometry. A: Correlation between maximal inspiratory pressure $\left(\mathrm{P}_{\mathrm{Imax}}\right)$ and $\mathrm{FEV}_{1}$. B: Correlation between $\mathrm{P}_{\mathrm{Imax}}$ and $\mathrm{FVC}$. C: correlation between inspiratory muscle endurance and total airway resistance (R5). D: Correlation between inspiratory muscle endurance and central airway resistance (R20).

$(103.67 \pm 16.82)(P=.003)$ and in subjects with $\mathrm{FEV}_{1}>80 \%(122.40 \pm 28.29)$ compared with the controls $(105.58 \pm 17.85)(P=.005)$. On the other hand, endurance was significantly lower in subjects without $P$. aeruginosa $(58.80 \pm 12.01)(P=.02)$ and with $\mathrm{FEV}_{1}>80 \%(60.0 \pm 11.83)(P=.050)$ compared with their healthy peers $(66.00 \pm 13.09$ and $66.43 \pm 13.03$, respectively). There was no significant difference in the strength and endurance of the subjects colonized by $P$. aeruginosa and with $\mathrm{FEV}_{1}<80 \%$ compared with their healthy controls (Fig. 2, B and D).

Separately correlating children and adolescents with cystic fibrosis colonized by $P$. aeruginosa and with $\mathrm{FEV}_{1}<80 \%, \mathrm{P}_{\text {Imax }}$ did not show a significant correlation with other pulmonary function parameters. However, there was a significant correlation between inspiratory muscle endurance and the airway resistances (R10 and R20). Likewise, when separately analyzing subjects with $P$. aeruginosa colonization and with $\mathrm{FEV}_{1}>80 \%$, there was a significant correlation of $\mathrm{P}_{\text {Imax }}$ with $\mathrm{FVC}, \mathrm{FEV}_{1}$, and total lung capacity, whereas endurance was not significantly correlated with other pulmonary function parameters. These results are presented in Table 3.

\section{Discussion}

The results of the present study show that individuals with cystic fibrosis and a milder presentation of the disease (ie, without chronic colonization by $P$. aeruginosa and with a $\mathrm{FEV}_{1}$ within the normal limits) present increased inspiratory muscle strength and reduced endurance compared with healthy individuals. On the other hand, subjects with chronic colonization by $P$. aeruginosa and reduction of $\mathrm{FEV}_{1}$ do not show differences compared with their healthy peers.

In general, considering the entire sample studied, our findings demonstrate that subjects with cystic fibrosis present an increase of inspiratory muscle strength. Other researchers found similar results. $3,4,28,29$ Dunnink et al ${ }^{4}$ suggest that the increased work of breathing due to airway obstruction could cause an effect of conditioning the respiratory muscles. On the contrary, some studies $^{5,12,30,31}$ showed a reduction of respiratory muscle strength, associating this finding with hyperinflation and malnutrition. Furthermore, Dassios et al ${ }^{32}$ showed that maximum respiratory pressures were significantly diminished in subjects with no severe lung disease; however, no correlation between $\mathrm{P}_{\text {Imax }}$ and BMI was found. The results of the present study in children and adolescents demonstrate a positive 

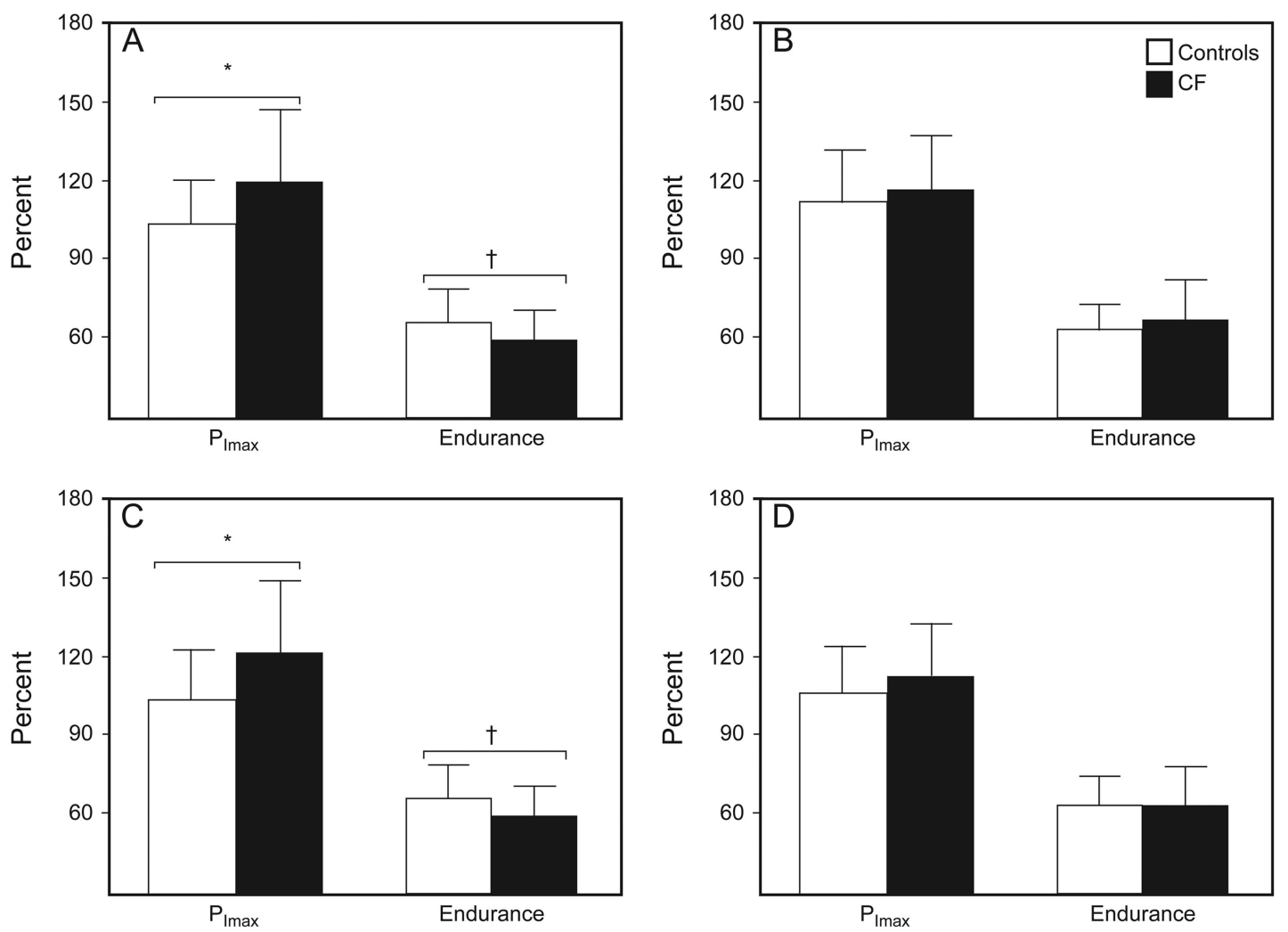

Fig. 2. Comparison of the inspiratory muscle strength $\left(P_{I \max }\right)$ and endurance between subjects with cystic fibrosis and healthy controls. A: Comparison between subjects with cystic fibrosis without colonization by $P$. aeruginosa and healthy subjects. B: Comparison between subjects with cystic fibrosis with colonization by $P$. aeruginosa and healthy individuals. C: Comparison between subjects with cystic fibrosis with $\mathrm{FEV}_{1}>80 \%$ and healthy subjects. D: Comparison between subjects with cystic fibrosis with $\mathrm{FEV}_{1}<80 \%$ and healthy subjects. $\mathrm{A}:{ }^{*}, P=.003 ; \dagger, P=.02 ; \mathrm{C}:{ }^{*}, P=.005 ; \mathrm{C}: \dagger, P=.050$.

Table 3. Pearson Correlation Coefficients for Airway Resistance, Spirometry, and Plethysmography in Relation to the Values of Strength and Endurance of the Inspiratory Muscles: Data Presented Separately for Subjects With and Without Colonization by P. aeruginosa and With $\mathrm{FEV}_{1}$ Greater or Less Than $80 \%$

\begin{tabular}{|c|c|c|c|c|c|c|c|c|}
\hline \multirow{2}{*}{ Variables } & \multicolumn{2}{|c|}{ No $P A(n=25)$} & \multicolumn{2}{|c|}{$P A(n=9)$} & \multicolumn{2}{|c|}{$\mathrm{FEV}_{1}>80 \%(n=21)$} & \multicolumn{2}{|c|}{$\mathrm{FEV}_{1}<80 \%(n=13)$} \\
\hline & $\mathrm{P}_{\text {Imax }}$ & Endurance & $\mathrm{P}_{\text {Imax }}$ & Endurance & $\mathrm{P}_{\text {Imax }}$ & Endurance & $\mathrm{P}_{\text {Imax }}$ & Endurance \\
\hline R5 & -0.33 & -0.01 & -0.21 & 0.64 & -0.38 & 0.09 & -0.15 & 0.49 \\
\hline $\mathrm{R} 10$ & -0.38 & 0.09 & 0.06 & $0.86^{*}$ & $-0.49 \dagger$ & 0.21 & 0.08 & $0.64 \dagger$ \\
\hline $\mathrm{R} 20$ & -0.32 & 0.06 & 0.05 & $0.82 *$ & -0.36 & 0.20 & 0.01 & $0.65 \dagger$ \\
\hline $\mathrm{FEV}_{1}$ & $0.46^{*}$ & -0.03 & 0.31 & 0.05 & $0.68^{*}$ & -0.24 & 0.41 & 0.42 \\
\hline FVC & $0.51 *$ & 0.07 & 0.26 & 0.23 & $0.62 *$ & -0.06 & 0.31 & $0.68 \dagger$ \\
\hline TLC & $0.63^{*}$ & -0.01 & -0.06 & 0.10 & $0.51 \dagger$ & 0.16 & 0.09 & 0.20 \\
\hline
\end{tabular}

$\overline{\text { No } P A}=$ without chronic colonization by $P$. aeruginosa

$P A=$ with chronic colonization by $P$. aeruginosa

$\mathrm{P}_{\text {Imax }}=$ maximum inspiratory pressure

TLC $=$ total lung capacity

R5 = total resistance of airways

$\mathrm{R} 10=$ resistance of the airway at a frequency of $10 \mathrm{~Hz}$

$\mathrm{R} 20=$ central resistance of airways.

$* P<.01$.

$\dagger P<.05$. 
correlation between $\mathrm{P}_{\text {Imax }}$ and BMI Z score, indicating influence of the nutritional aspect on respiratory muscle strength. However, in the study by Ziegler et al, ${ }^{5}$ the reduction of strength was not related to the nutritional status in adult subjects with cystic fibrosis. It can be suggested that airway obstruction and compromised nutritional status interact in opposite directions in the different subjects, making it difficult to separately interpret the correlations obtained.

Unlike respiratory muscle strength, few studies have evaluated inspiratory muscle endurance in subjects with cystic fibrosis. In 1977, Keens et al, ${ }^{11}$ despite using a different methodology, demonstrated increased endurance, supposedly due to the adaptation of the muscles to the chronic stress of ventilating against a load generated by airway obstruction. On the other hand, few studies found a reduction of this capacity, and they did not find evidence of a relationship with nutritional status, presence of airway obstruction, pulmonary hyperinflation, respiratory muscle strength, or maximum capacity for exercise..$^{3,12}$ Likewise, our results did not present a correlation of endurance with BMI Z score or with lung volumes. When we analyzed the entire sample studied, we did not identify differences in endurance compared with healthy controls. It is possible that this is related to the inclusion of many young subjects with little respiratory compromise in the present study and to the variability of endurance according to different levels of pulmonary involvement. In a study of subjects with COPD, diminished endurance was related to pulmonary hyperinflation. ${ }^{9}$ However, our results demonstrate a significant correlation with airway resistance, indicating that increased resistance may influence the regulation of endurance.

Colonization by $P$. aeruginosa is associated with greater deterioration of lung function and is seen as a limiting factor in subjects' survival. ${ }^{33,34}$ Our results show that children and adolescents with chronic $P$. aeruginosa colonization present worse $\mathrm{FEV}_{1}$ values and increased total and central airway resistances, corroborating the study by Welsh et al, ${ }^{35}$ who demonstrated that $P$. aeruginosa infection is a major predictor for $\mathrm{FEV}_{1}$ decline. Likewise, subjects with $\mathrm{FEV}_{1}$ reduction, regardless of $P$. aeruginosa colonization, present increased resistance of the airways, RV, and functional residual capacity. ${ }^{36}$ Subjects with a milder presentation of the disease show greater strength and less inspiratory muscle endurance. On the contrary, subjects with diminished pulmonary function and $P$. aeruginosa colonization do not present any difference in strength and endurance compared with healthy individuals. Thus, it is possible that patients with cystic fibrosis develop decreasing muscle strength and increasing endurance, demonstrating that the decline of pulmonary status affects these 2 parameters differently, although a longitudinal study would be necessary to specifically answer this question. More- over, a reduction of endurance has already been demonstrated in adults, ${ }^{12}$ and further studies showed a reduction of $15-40 \%$ of $\mathrm{P}_{\text {Imax }}$ in subjects with moderate air flow obstruction. These findings could suggest that at advanced stages of the disease, patients are no longer able to maintain respiratory muscle strength.

Our findings also demonstrate that in individuals with cystic fibrosis, inspiratory muscle strength is more dependent on pulmonary function, since it was correlated with spirometry and plethysmography. However, endurance appears to depend more on airway resistance, especially with the central component, since we found a correlation with R20. Thus, we can suggest that the increased airway resistance over time generates increased muscle endurance, because ventilation with an increased load caused by airway obstruction can lead to endurance training. This training, on the other hand, does not appear to generate a significant effect on inspiratory muscle strength. Further, diminished pulmonary function, as a consequence of disease progression and associated with increased RV, would have the opposite effect, contributing to weakening the inspiratory muscles, since subjects with less pulmonary involvement present increased muscle strength. This may be explained by the positioning of the diaphragm dome and diminished zone of diaphragm apposition, so that the traction forces of the diaphragm fibers are placed in an almost horizontal position, ${ }^{37}$ generating a mechanical disadvantage, with reduction of their capacity to distend and with consequent reduction of inspiratory muscle strength..$^{38}$ As far as we know, this is the first study demonstrating that strength and endurance of inspiratory muscles depend on the degree of pulmonary involvement and are associated with distinct pathophysiological mechanisms in children and adolescents with cystic fibrosis.

The main limitation of our study is the use of analyses with subsamples, since the reduced sample size in subgroups may influence the results. However, post-analysis power calculations indicate sufficient power to support the conclusions. The use of controls at a proportion of 1:2 may have helped to minimize these effects in the present study.

\section{Conclusions}

In conclusion, children and adolescents with cystic fibrosis with no colonization by $P$. aeruginosa and normal lung function present increased inspiratory muscle strength and decreased endurance compared with healthy individuals, indicating that changes in respiratory muscle function seem to be distinctly associated with pulmonary involvement. In addition, strength appears to be more closely related to lung function parameters, whereas endurance has a greater correlation with airway resistance. 


\section{Inspiratory Muscle Strength and Endurance In CF}

\section{REFERENCES}

1. Gibson RL, Burns JL, Ramsey BW. Pathophysiology and management of pulmonary infections in cystic fibrosis. Am J Respir Crit Care Med 2003;168(8):918-951.

2. Heinzmann-Filho J, Marostica PJ, Donadio MV. Ventilatory muscle strength in cystic fibrosis patients: a literature review. Monaldi Arch Chest Dis 2012;77(3):134-138.

3. de Jong W, van Aalderen WM, Kraan J, Koëter G, van der Schans CP. Inspiratory muscle training in patients with cystic fibrosis. Respir Med 2001;95(1):31-36.

4. Dunnink MA, Doeleman WR, Trappenburg JC, de Vries WR. Respiratory muscle strength in stable adolescent and adult patients with cystic fibrosis. J Cyst Fibros 2009;8(1):31-36.

5. Ziegler B, Lukrafka JL, de Oliveira Abraão CL, Rovedder PM, Dalcin Pde T. Relationship between nutritional status and maximum inspiratory and expiratory pressures in cystic fibrosis. Respir Care 2008;53(4):442-449.

6. Lands LC, Heigenhauser GJ, Jones NL. Analysis of factors limiting maximal exercise performance in cystic fibrosis. Clin Sci 1992;83(4): 391-397.

7. Lands LC, Heigenhauser GJ, Jones NL. Respiratory and peripheral muscle function in cystic fibrosis. Am Rev Respir Dis 1993;147(4): 865-869.

8. Brancaleone P, Perez T, Robin S, Neviere R, Wallaert B. Clinical impact of inspiratory muscle impairment in sarcoidosis. Sarcoidosis Vasc Diffuse Lung Dis 2004;21(3):219-227.

9. Perez T, Becquart LA, Stach B, Wallaert B, Tonnel AB. Inspiratory muscle strength and endurance in steroid-dependent asthma. Am J Respir Crit Care Med 1996;153(2):610-615

10. Fauroux B. Respiratory muscle testing in children. Paediatr Respir Rev 2003;4(3):243-249.

11. Keens TG, Krastins IR, Wannamaker EM, Levison H, Crozier DN, Bryan AC. Ventilatory muscle endurance training in normal subjects and patients with cystic fibrosis. Am Rev Respir Dis 1977;116(5): 853-860.

12. Leroy S, Perez T, Neviere R, Aguilaniu B, Wallaert B. Determinants of dyspnea and alveolar hypoventilation during exercise in cystic fibrosis: impact of inspiratory muscle endurance. J Cyst Fibros 2011; 10(3):159-165.

13. Vandenbranden SL, McMullen A, Schechter MS, Pasta DJ, Michaelis RL, Konstan MW, et al. Lung function decline from adolescence to young adulthood in cystic fibrosis. Pediatr Pulmonol 2012;47(2): 135-143.

14. Nixon GM, Armstrong DS, Carzino R, Carlin JB, Olinsky A, Robertson CF, Grimwood K. Clinical outcome after early Pseudomonas aeruginosa infection in cystic fibrosis. J Pediatr 2001;138(5):699704.

15. Courtney JM, Bradley J, Mccaughan J, O'Connor TM, Shortt C, Bredin CP, et al. Predictors of mortality in adults with cystic fibrosis. Pediatr Pulmonol 2007;42(6):525-532.

16. Dassios TG, Katelari A, Doudounakis S, Dimitriou G. Chronic Pseudomonas aeruginosa infection and respiratory muscle impairment in cystic fibrosis. Respir Care 2014;59(3):363-370.

17. Esteves AR, Solé D, Ferraz M. Adaptation and validity of the ATSDLD-78-C questionnaire for asthma diagnosis in children under 13 years of age. Braz Ped News 1999;1:3-5.

18. Borman H, Ozgür F. A simple instrument to define the Frankfurt horizontal plane for soft-tissue measurements of the face. Plast Reconstr Surg 1998;102(2):580-581.

19. de Onis M, Onyango AW, Borghi E, Siyam A, Nishida C, Siekmann J. Development of a WHO growth reference for school-aged children and adolescents. Bull World Health Organ 2007;85(9):660-667.

20. Nowowiejska B, Tomalak W, Radliński J, Siergiejko G, Latawiec W, Kaczmarski M. Transient reference values for impulse oscillom- etry for children aged 3-18 years. Pediatr Pulmonol 2008;43(12): 1193-1197.

21. Wanger J, Clausen JL, Coates A, Pedersen OF, Brusasco V, Burgos $\mathrm{F}$, et al. Standardisation of the measurement of lung volumes. Eur Respir J 2005;26(3):511-522.

22. Koopman M, Zanen P, Kruitwagen CL, van der Ent CK, Arets HG. Reference values for paediatric pulmonary function testing: the Utrecht dataset. Respir Med 2011;105(1):15-23.

23. Chavasse R, Johnson P, Francis J, Balfour-Lynn I, Rosenthal M, Bush A. To clip or not to clip? Noseclips for spirometry. Eur Respir J 2003;21(5):876-878.

24. American Thoracic Society, European Respiratory Society. ATS/ERS recommendations for standardized procedures for the online and offline measurement of exhaled lower respiratory nitric oxide and nasal nitric oxide, 2005. Am J Respir Crit Care Med 2005;171(8):912-930.

25. Quanjer PH, Stanojevic S, Cole TJ, Baur X, Hall GL, Culver BH, et al. Multi-ethnic reference values for spirometry for the 3-95-yr age range: the global lung function 2012 equations. Eur Respir J 2012; 40(6):1324-1343.

26. Heinzmann-Filho JP, Vidal PCV, Jones MH, Donadio MVF. Normal values for respiratory muscle strength in healthy preschoolers and school children. Respir Med 2012;106(12):1639-1646.

27. Domènech-Clar R, López-Andreu JA, Compte-Torrero L, De DiegoDamiá A, Macián-Gisbert V, Perpiñá-Tordera M, Roqués-Serradilla JM. Maximal static respiratory pressures in children and adolescents. Pediatr Pulmonol 2003;35(2):126-132.

28. Zanchet RC, Chagas AMA, Melo JS, Watanabe PY, Simões-Barbosa A, Feijo G. Influence of the technique of re-educating thoracic and abdominal muscles on respiratory muscle strength in patients with cystic fibrosis. J Bras Pneumol 2006;32(2):123-129.

29. Dufresne V, Knoop C, Van Muylem A, Malfroot A, Lamotte M, Opdekamp C, et al. Effect of systemic inflammation on inspiratory and limb muscle strength and bulk in cystic fibrosis. Am J Respir Crit Care Med 2009;180(2):153-158.

30. Fauroux B, Boulé M, Lofaso F, Zérah F, Clément A, Harf A, Isabey D. Chest physiotherapy in cystic fibrosis: improved tolerance with nasal pressure support ventilation. Pediatrics 1999;103(3):e32.

31. Keochkerian D, Chlif M, Delanaud S, Gauthier R, Maingourd Y, Ahmaidi S. Timing and driving components of the breathing strategy in children with cystic fibrosis during exercise. Pediatr Pulmonol 2005;40(5):449-456.

32. Dassios T, Katelari A, Doudounakis S, Mantagos S, Dimitriou G. Respiratory muscle function in patients with cystic fibrosis. Pediatr Pulmonol 2013;48(9):865-873

33. Kosorok MR, Zeng L, West SE, Rock MJ, Splaingard ML, Laxova A, et al. Acceleration of lung disease in children with cystic fibrosis after Pseudomonas aeruginosa acquisition. Pediatr Pulmonol 2001; 32(4):277-287.

34. Li Z, Kosorok MR, Farrell PM, Laxova A, West SE, Green CG, et al. Longitudinal development of mucoid Pseudomonas aeruginosa infection and lung disease progression in children with cystic fibrosis. JAMA 2005;293(5):581-588.

35. Welsh L, Robertson CF, Ranganathan SC. Increased rate of lung function decline in Australian adolescents with cystic fibrosis. Pediatr Pulmonol 2014;49(9):873-877.

36. Andrade EDF, Fonseca DLOD, Silva FADAE, Menna-Barreto SS. Spirometry evolution assessment of cystic fibrosis. J Pneumol 2001; 27(3):130-136

37. Levine S, Nguyen T, Shrager J, Kaiser L, Camasamudram V, Rubinstein N. Diaphragm adaptations elicited by severe chronic obstructive pulmonary disease: lessons for sports science. Exerc Sport Sci Rev 2001;29(2):71-75.

38. McConnell AK, Romer LM. Dyspnoea in health and obstructive pulmonary disease. Sports Med 2004;34(2):117-132. 